\title{
Development of Problem Solving Skills by Integration Learning Following STEM Education for Higher Education
}

\author{
Titiya Netwong
}

\begin{abstract}
The objectives of this research were to development of problem solving skills and learning achievement in problem solving by integration learning following STEM education. The sample used for experimental group consisted of 33 undergraduate students in the Strategic Information Management course in the 2016 academic year, at Suan Dusit University. The research instruments was the problem solving skills evaluate and problem solving achievement. The data obtained were analyzed by using mean, standard deviation, and t-test dependent. The results of the study were as follows: 1) the problem solving skills of experimental sample increased $13.03 \%$. The comparison of problem solving skills before and after undertaking integration learning following STEM education was different at significant 0.05 . Over all problem solving skills after undertaking teaching $(X=8.47)$ was higher than before teaching ( $\mathrm{X}=3.91)$. 2) The learning achievement in problem solving of experimental sample increased $17.92 \%$. The comparison of learning achievement in problem solving before and after undertaking integration learning following STEM education was different at significant 0.05 . Over all learning achievement in problem solving undertaking teaching ( $\mathrm{X}=13.85$ ) was higher than before teaching ( $\mathrm{X}=7.58$ ).
\end{abstract}

Index Terms-Problem solving skills, STEM education, higher education, integration learning

\section{INTRODUCTION}

Currently, integrated learning based on STEM education has been interested in managing all sectors including teachers and educational personnel. Teaching with science learning management focus on lifelong education with a flexible approach, encourage students to practice critical thinking and problem solving and the pursuit of self-knowledge, information, media and technology skills through learning management guidelines reflect the STEM education. This is a guideline that fosters learning in the 21 st century.

STEM education comes from the words Science, Technology, Engineering, and Mathematics education as a method of teaching and learning. STEM education integration of science, technology, engineering, and mathematics by focusing on creating knowledge to solve problems. Also focus on developing new processes, productivity useful to the lifestyle, and innovations to enhance competitiveness. STEM Education focuses on the

Manuscript received October 25, 2017; revised April 12, 2018. This work was supported in part by Suan Dusit University Department of Research and Development.

Netwong T. is with Faculty of Science and Technology, Suan Dusit University, Thailand (e-mail: titiya_net@dusit.ac.th). process of applying this knowledge to the search, selection, and selection of the most appropriate ways to solve problems related to life and work [1]-[4].

A guideline for learning management in STEM education will focus on the problem solution project or innovate by integrating science knowledge, and mathematics contributes to technology that exploits. Engineering in STEM education is about making modifications to prototypes, including design, manufacturing, or service, by applying knowledge, science, mathematics and technology, which is different from general integrated learning management. STEM Education connection to knowledge of science. However, the STEM education will focus on the use of engineering knowledge and technology. But in Thailand, there is no course in engineering at the basic level. Therefore, it is the implementation of engineering processes to solve problems rather than engineering studies [1], [2].

It is said that integrated learning following STEM education helps learners develop their thinking skills, Information Technology skills, problem solving skills, and communication skills. This skill is a 21 st century learning skill that students must have. In addition, learners have a holistic knowledge that can be linked or applied in everyday life. Problem solving skills are one of the most important skills for human beings. Because humans face everyday problems, to solve the problem is not only to know, to know and to use the brain or to develop skills alone. It is also a skill that can develop attitudes, values, knowledge, understanding, and social conditions. In the education system, it is important to focus on developing students' problem-solving skills [5], [6].

Therefore, integrated learning following STEM education according to the study plan aims to develop problem solving skills through integrated learning. STEM education focused on solving complex, real world problem using a case study approach. Students work in small groups to investigate, create solutions to problems that could have multiple solutions and method for reaching them. [7] It is a guideline that can be applied to the students to have the knowledge and skills to solve problems. This is an important feature of $21 \mathrm{st}$ century learners, who have the opportunity to learn together in the project to solve problems in accordance with the way of learning. Encourage students to create concrete works on the basis of solving social or community problems. The results of the research will be projected to solve social or community problems and to promote the application of problem solving. This will be a guide for the institution to adopt the learning model, to apply, to develop, to learn, and to develop the skills needed in the 21 st century. 


\section{MATERIALS AND Methods}

\section{A. Subject Selection and Criterions}

The sample group to this study consisted of 33 undergraduate students enrolled in the Information Technology Program who registered the course of Strategic Information Management in 2016 academic year.

\section{B. Instrument}

The research instruments were as follows:

1) The problem solving evaluates.

2) The learning achievement in problem solving.

\section{Research design}

One group pretest-posttest design was research design in this study

\section{$\mathrm{T}_{1} \times \mathrm{T}_{2}$}

$\mathrm{X}$ : Experiment or Treatment

$\mathrm{T}_{1}$ : Pretest

$\mathrm{T}_{2}$ : Posttest

\section{Statistic}

The statistical package was uses for mean, standard deviation, t-test dependent.

\section{E. Methods}

1) Using the instruments, there were the problem solving evaluates and the learning achievement in problem solving to pretest of the experimental group.

2) The experimental group will learning by using integrated learning following STEM education for 12 weeks, the steps as follows:

Week 1: Prepares environment and students.

- The classrooms and facilities, both of online and face to face

- Students work in small groups 4-5 persons to investigate

Week 2-3: Steps to consider issues.

- Encourage learners to be aware of issues. What is the problem in everyday of life?

- Community participation

- Using technology tool to investigate and research

Week 4-5: Data Collection Process.

- Scientific knowledge finds related ideas

- Set up a project-based approach to problem solving

Week 6: Planning a project.

- Develop innovation and solution, reviewing knowledge, checking information, by using science in the problem solving process, and use of related hardware and software

Week 7-8: Project implementation stage.

- Actually follow the sequence of steps and procedures laid down, include test, validation, and evaluation in progress.

Week 9-10: Summarize, evaluate, discuss, and write reports based on scientific facts.

- Testing and presentation of engineering results, and mathematical interpretation of mathematical calculations
Week 11-12: Designed presentation.

- Present a problem-solving project in a way that is easy to understand, understandable, and accessible. Based on media design technology and present the results with technology

3) Using the instruments, there were the problem solving evaluates and the learning achievement in problem solving to posttest of the experimental group. The contents of learning achievement in problem solving were application of strategic information systems and strategic of information technology support systems. The indicators of problem solving skills were identify problems, possible solution, provide a way to solve the problem, choose the best method to solve the problem, tell the benefits of the solution, ability to present innovation solution, and application of problem solving in other situations.

\section{RESUlTS AND DISCUSSION}

\section{A. The Problem Solving Skills}

Development of problem solving skills could use integrated learning following STEM education. The students' problem solving skills before and after undertaking integrated learning following STEM education was shown in figure 1.

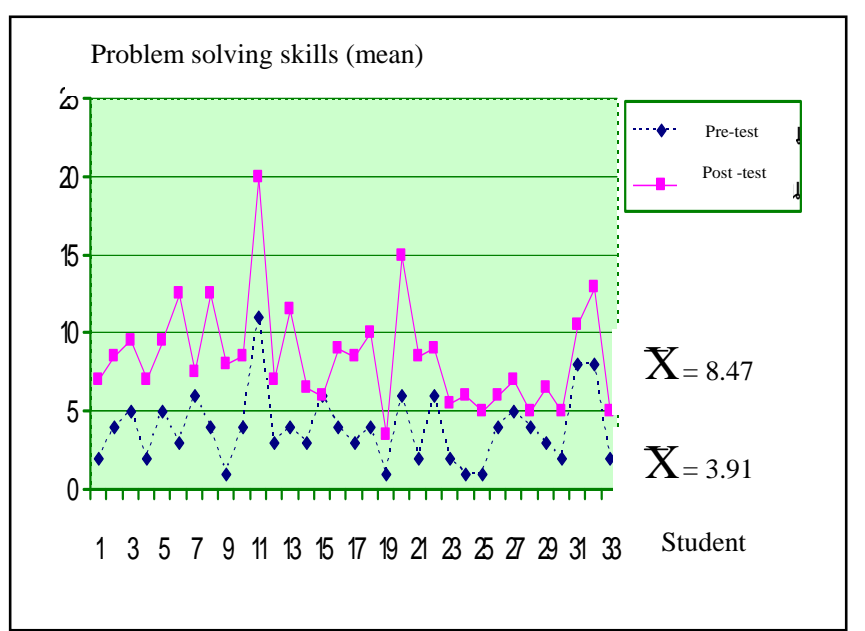

Fig. 1. The problem solving skills before and after undertaking integrated learning following STEM education.

Fig. 1 shown the problem solving skills before and after undertaking integrated learning following STEM education of students. Problem solving skills of everybody after treatment was higher than before treatment.

The comparison of the pre-test and post-test score by using the integrated learning following STEM education was found at the significance level of 0.05 . The problem solving skills before and after undertaking integrated learning following STEM education were different, shown in Table I.

TABLE I: The Problem Solving SKILls PRE-TEST AND Post-Test

\begin{tabular}{c|c|c|c|c|c}
\hline $\begin{array}{c}\text { Problem } \\
\text { solving skills }\end{array}$ & $\bar{x}$ & S.D. & t & df & Sig. \\
\hline Pre-test & 3.91 & 2.26 & 11.13 & 32 & $0.00^{*}$ \\
Post-test & 8.47 & 3.37 & & & \\
\hline \hline
\end{tabular}


Table I shown the problem solving skills pre-test and post-test of students. Problem solving skills post-test was higher than pre-test. The integrated instructional following STEM education can improve students' problem-solving skills. In the first step, the learners divided the group into project based problems. The project implementation was to develop innovative solutions through organizational problems by using information technology. So there is teamwork to choose common issues. Group members understand the problem and have common goals to solve the problem. While conducting the activity, the student expressed his or her independent opinions. It promotes a learning culture. The new 21 st century learning culture must be learned by practice, work, project, and will work more as a team. The goal of the course is integration learning has skillfully practiced social skills and other skills in learning following STEM education [8]. Data must be collected. Find concepts that are relevant to solving problems and evaluate possibilities. The learners use the technology to retrieve information. The community or organization involvement and participation were to solving problem. Find the right way and meet the needs of the community or organization. It is said that the integration of science and science with the problem solving process. Technology with using information retrieval from information resources, Mathematics with assessment, interpretation, and engineering by identifying problems, finding the right ideas, and present the results. Thus, learning following STEM helps learners develop their thinking skills. Information technology skills, problem solving skills, and communication skills are the basic of $21 \mathrm{st}$ century learning skill that students must have. In addition, learners have a holistic knowledge that can be linked or applied in everyday of life. In addition, while the students complete the project until the project is completed. Instructors must act as consultants, to facilitate, and keep track of student projects on a regular basis. The use of information technology to communicate, and job presentation, it will make the students contact the instructor more quickly. And further enhance the students' information technology skills [9]. Teachers should focus on problem-based learning, project-based learning management, learning activities that focus on working together as a group, the exchange of learning and feedback to students, to check the knowledge of the students regularly. That the teaching of the student's learning is a teacher's duty. Learning to focus on how to attract the attention of student engagement, which is the responsibility of the instructor. By designing the learner to collaborate, researching, applying, and reflecting together, reflect on why. How does it work better? It makes learning a challenge [8].

\section{B. The Learning Achievement in Problem Solving}

Development of the learning achievement in problem solving could using by integrated learning following STEM education. The students' learning achievement in problem solving before and after undertaking integrated learning following STEM education was shown in Fig. 2.

Fig. 2 had shown the learning achievement in problem solving before and after undertaking integrated learning following STEM education of students. Learning achievement in problem solving of everybody after treatment was higher than before treatment.

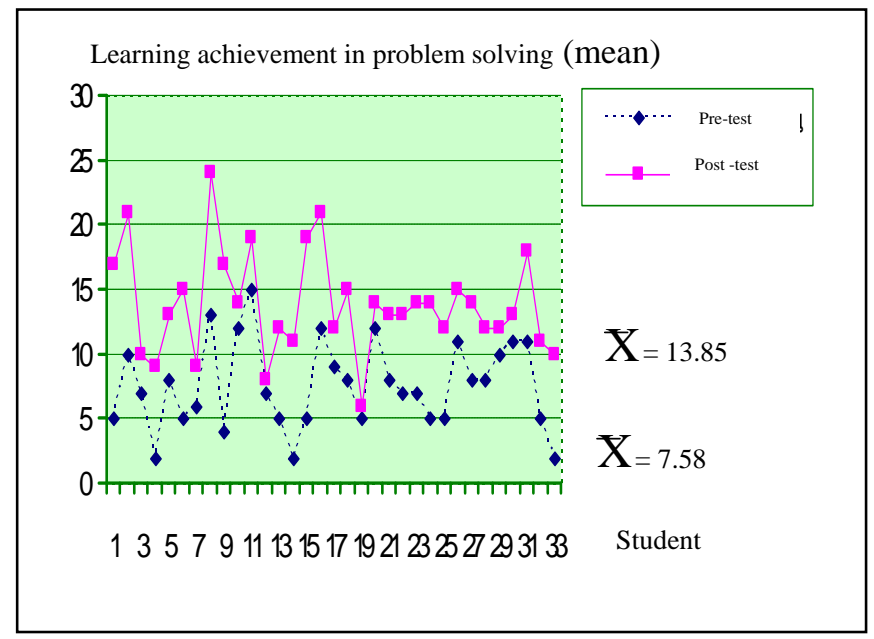

Fig. 2. The learning achievement in problem solving before and after undertaking integrated learning following STEM education.

The comparison of the learning achievement in problem solving of the experiment between the pre-test and post-test was at the significance level of 0.05 . The learning achievement in problem solving before and after undertaking integrated learning following STEM education were different, shown in table II.

TABLE II: THE LEARNING ACHIEVEMENT IN PROBLEM SOLVING PRE-TEST AND POST-TEST

\begin{tabular}{c|c|c|c|c|c}
\hline \hline $\begin{array}{c}\text { Learning } \\
\text { achievement } \\
\text { in problem } \\
\text { solving }\end{array}$ & $\bar{x}$ & S.D. & $\mathbf{t}$ & df & Sig. \\
\hline Pre-test & 7.58 & 3.34 & 10.134 & 32 & $0.00^{*}$ \\
Post-test & 13.85 & 3.99 & & & \\
\hline \hline
\end{tabular}

$* p<.05$

Table II shown the learning achievement in problem solving pre-test and post-test of students. The means of post-test were higher than pre-test at significant 0.05 . Corresponds to the studied, the ability to solve problems. The problem solving process before and after the experiment was statistically significantly different at the 0.01 level. After learning by STEM, the ability to solve problems was higher. This reflects that if the students have high problem solving skills. It can solve problems in life, and future career well [6]. In accordance with the concept of learning STEM educational management of science education is the integration of science, technology, engineering, and mathematics by focusing on bringing knowledge to life. Also focus on developing new processes, productivity, useful to the lifestyle, increase knowledge, to integrate science, technology, engineering processes, and mathematics to solve problems in life and future careers [4]. Consistent with the concept of the learning process is a science-based learning activity designed to complement learning, science, mathematics and technology to be more complete [3]. By integrating all three subjects through the engineering design process to promote learning and skill building, focusing on 
building knowledge for problem solving. It is a fun, challenging, and challenging learning experience. But STEM education has focused on the process of applying this knowledge to the search, selection, and selection of the most appropriate ways to solve problems related to life and work. In addition, promoting of 21 st century learning culture, learners must keep abreast of the changing world. Social change makes the changes lifestyle, way of working change. The desirable learning culture must have a significant component. A culture of courage, experimentation, a culture of sharing knowledge, culture of teamwork, friendly culture with knowledge, a good culture to manage a talented team who are knowledge workers, and creating a community of practitioners.

\section{CONClusion}

The problem solving is considered on the list of $21 \mathrm{st}$ century skills. Using project based following STEM education as it is being learned, applying skills like problem solving and creativity to the content knowledge, innovation increases motivation and improves learning outcomes. The project had students exercising many of the 21 st century skills: problem solving, communication, collaboration, information and ICT literacy, flexibility and adaptability, self-direction, leadership, and responsibility [7]. Project outcomes are tied to curriculum and learning goals. Project following STEM education is based on authentic, real world problems and solution those students reaching it. Students are responsible for designing and managing much of their own learning. STEM is preparing students to contribute to the world of work and civic life, well-trained workers. Especially in the technical areas of Science, Technology, Engineering, and Mathematics are become learning for work and life to helping as many students as possible to apply 21 st century skills.

\section{APPENDIX}

The activities of integrated learning following STEM education had shown in Fig. 3- 7.

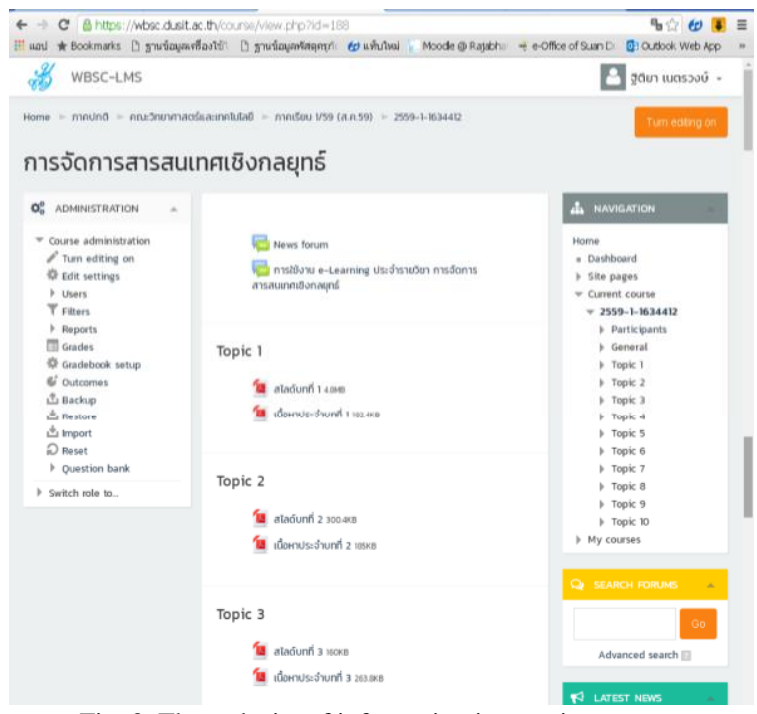

Fig. 3. The web site of information integration course.
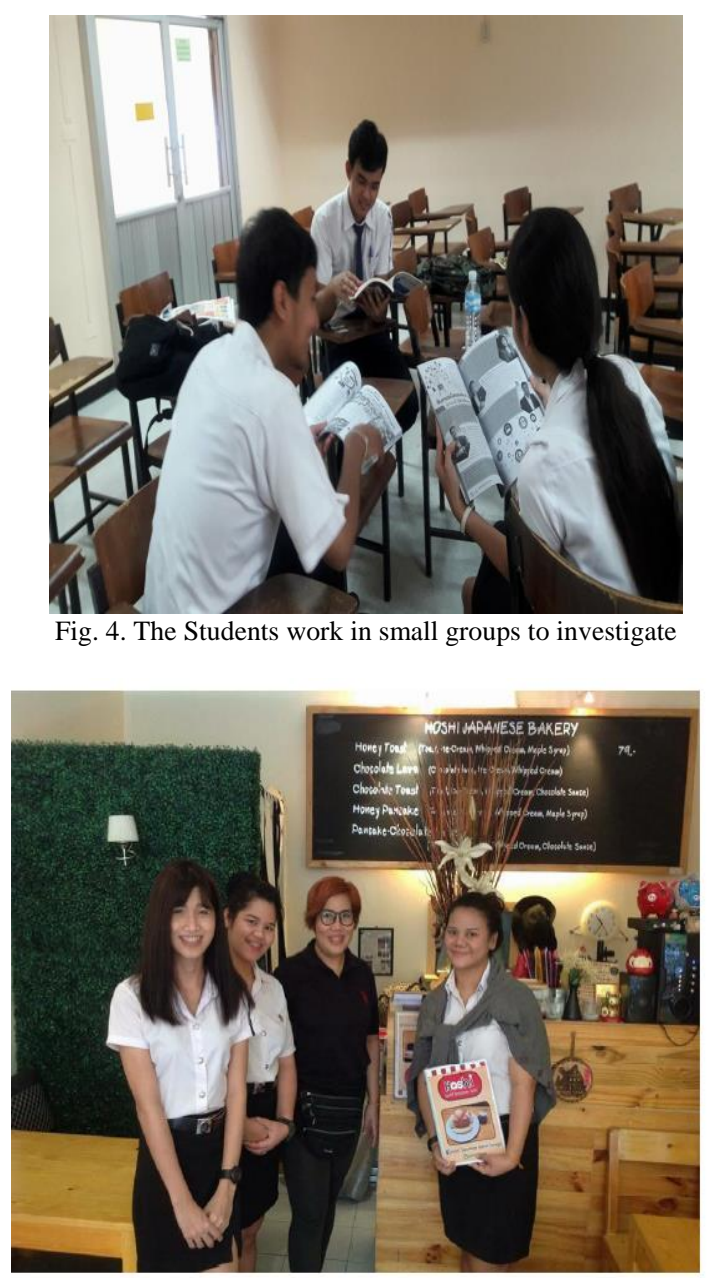

Fig. 5. Steps to consider issues.

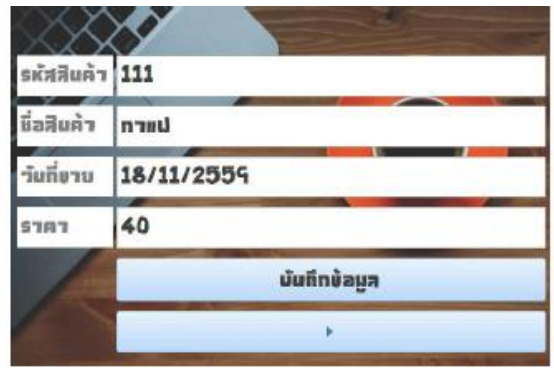

บรรยาย : หน้า รัน ของฐานข้อมูล

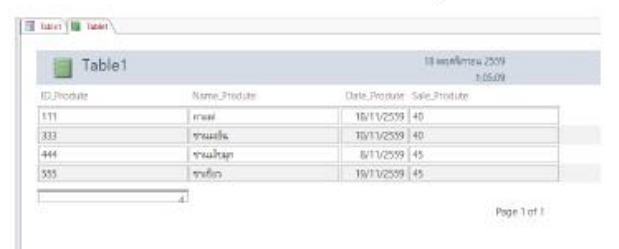

Fig. 6. Planning a project.

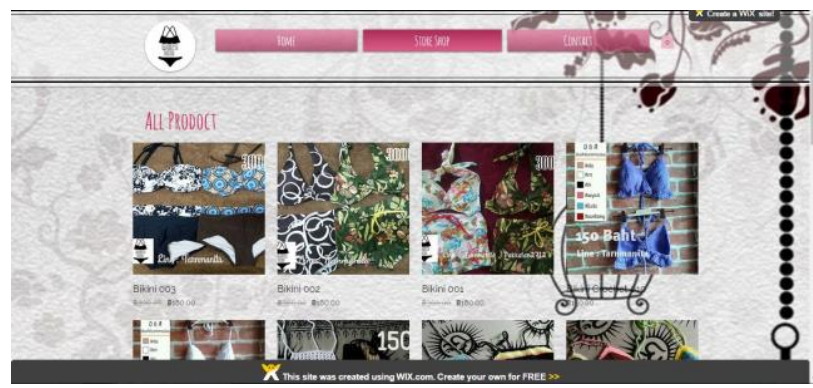




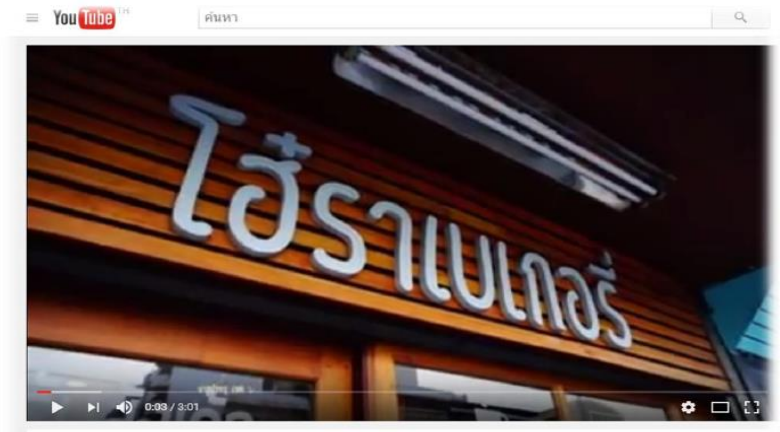

รานโช่ราเบเกอริ

Fig. 7. Project implementation stage and up load project to YouTube.

\section{REFERENCES}

[1] M. Julawatthanaton, "STEM education in Thailand and STEM ambassadors," IPST Magazine, vol. 42, no. 185, pp. 14-18, 2013.

[2] The Institute for the Promotion of Teaching Science and Technology, STEM Education, Bangkok: The Institute for the Promotion of Teaching Science and Technology (IPST), 2014.

[3] W. Wongkitrungroung and A. Jittaruke, Skills for The Future: Education for $21^{\text {st }}$ Century, Bangkok: Open World, 2011.

[4] S. Chanprasert, "Instructional management in science and essential skills in the 21st century," IPST Magazine, vol. 42, no. 185, pp. 10-13, 2013.

[5] R. Plangwatthana, "STEM education and instructional management in earth, astronomy and space," IPST Magazine, vol.42, no. 185, pp. $19-22,2013$
[6] W. Laopaisalpong, "A study of the problem solving ability and the interest in mathayomsuksa III student through the problem solving method and the teacher's manual," Master thesis, Master of Education Degree in Secondary Education, Graduate School, Srinakharinwirot University, 2011.

[7] B. Trilling and C. Fadel, 21 ST Century Skills: Learning for Life in Our Times, San Francisco: Jossey-Bass A Wiley Imprint, 2009.

[8] W. Panich, Learning Method for the Students in $21^{s t}$ Century, Bangkok: TathaPublication Co.ltd, 2012.

[9] K. Boonphak, "Skill and technical learning management to excellence," Journal of Industrial Education, vol. 14, no. 1, pp. 1-4, 2015.

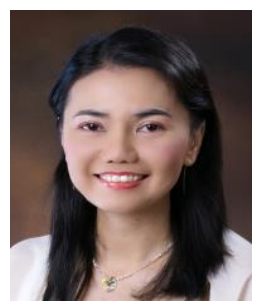

Netwong T. was born in Kalasin province, Thailand. She completed her doctor of philosophy degree in educational communications and technology in 2010.

She is a lecturer at the Faculty of Science and Technology, Suan Dusit University in Thailand. The research experience as follows: Development of Reading Promotion Activities Model to Enhance Reading Habit and Life Skill: Health Mind and Body for Early Childhood, and Development of Problem Solving Skills by Integration Learning Following STEM Education.

Assist. Prof. Dr. Titiya Netwong was memberships in associate civil engineer of Council of Engineers, Thailand. 